\title{
CdO:Ag thin films with enhanced visible light photocatalytic activity against metanil yellow
}

\author{
G. Shanmugavel ${ }^{1} \cdot$ A. R. Balu ${ }^{1}$ (1) - V. S. Nagarethinam ${ }^{1} \cdot$ S. Ravishankar ${ }^{1} \cdot$ M. Suganya $^{1} \cdot$ S. Balamurugan ${ }^{1}$. \\ K. Usharani ${ }^{2} \cdot$ C. Kayathiri ${ }^{1} \cdot$ M. Karthika ${ }^{1,3}$
}

(c) Springer Nature Switzerland AG 2019

\begin{abstract}
The photodegradation quality of Ag-doped $\mathrm{CdO}$ (CdO:Ag) thin films deposited using perfume atomizer has been reported in this paper. Ag concentration in CdO is varied as $0,1,2$ and $3 \mathrm{wt} \%$, respectively. XRD studies reveal cubic crystal structure for all the CdO:Ag thin films ruling out the presence of any secondary phases and decreased crystallite size was observed with Ag doping. CdO:Ag films surfaces are composed of cauliflower shaped grains and EDX spectra ascertains that $\mathrm{Ag}$ has been successfully incorporated into the $\mathrm{CdO}$ lattice. Optical band gap tends to increase with increase in $\mathrm{Ag}$ concentration. Electrical resistivity showed a decreasing trend with increase in Ag concentration. Photocatalytic tests against metanil yellow confirmed that the Ag-doped $\mathrm{CdO}$ films exhibit better degradation efficiency than the undoped film and an efficiency of $84.44 \%$ was realized for the $2 \mathrm{wt} \% \mathrm{Ag}$-doped CdO catalyst. The recycle tests confirmed the reusable nature of the CdO:Ag catalysts.
\end{abstract}

Keywords Doping $\cdot$ Cubic structure $\cdot$ Photocatalytic activity $\cdot$ Band gap

Mathematics Subject Classification 74K35

JEL Classification Y10

\section{Introduction}

Cadmium oxide $(\mathrm{CdO})$ in thin film form finds applications in solar cells, smart windows, optoelectronic devices, gas sensors, anti-reflecting coatings, etc. due to its dual combination of good optical and electrical properties [1]. The high electrical conductivity, surface morphology and large surface to volume ratio possessed make $\mathrm{CdO}$ suitable for sensing gases such as LPG, ethanol, ammonia gas, etc. [2]. $\mathrm{CdO}$ is photoactive due to its n-type conductivity and due to its narrow direct band gap of $2.3 \mathrm{eV}$ [3]. The high optical absorption and charge carrier mobility makes $\mathrm{CdO}$ suitable for dye degradation [4]. However, the low resistivity, stability, band gap and toxicity restrict $\mathrm{CdO}$ in many technological applications. As the conductivity of $\mathrm{CdO}$ is dominated by the oxygen vacancies and cadmium interstitials [5], tuning them through dopants could enhance its resistivity and stability [6]. In photocatalytic applications, $\mathrm{CdO}$ exhibits low degradation efficiency due to its shortened band gap which cause the photogenerated electrons and holes to recombine rapidly. Also, the release of cadmium ions is a major concern from the environmental point of view due to its natural toxicity. These two drawbacks can be removed by doping $\mathrm{CdO}$ with suitable metallic ions. The non-stoichiometric structure of $\mathrm{CdO}$ with cadmium interstitials provide a good environment for dopants to

$\triangle$ A. R. Balu, arbalu757@gmail.com | ${ }^{1}$ PG and Research Department of Physics, AVVM Sri Pushpam College, Poondi, Tamilnadu, India. ${ }^{2}$ PG and Research Department of Physics, Thiru Vi Ka Govt College, Thiruvarur, Tamilnadu, India. ${ }^{3}$ PG and Research Department of Physics, Bonsecours College for Women, Thanjavur, Tamilnadu, India. 
diffuse in its lattice and hence enhanced resistivity, stability, band gap could be realized and the release of $\mathrm{Cd}^{2+}$ ions are very much suppressed.

Literature results showed that dopants with smaller ionic radii than $\mathrm{Cd}^{2+}$ such as $\mathrm{Mg}, \mathrm{Mn}, \mathrm{Al}$, and $\mathrm{Sn}$ enhanced the structural, optical and electrical properties of $\mathrm{CdO}$ [7-10]. Beside these, metal ions such as $\mathrm{Ba}$ [11] and $\mathrm{Sr}$ [12] with ionic radii greater than $\mathrm{Cd}^{2+}$ also influenced the physical properties of $\mathrm{CdO}$. In this work, a transition metal ion with ionic radius greater than that of $\mathrm{Cd}^{2+}$ is used as dopant to enhance the physical properties of $\mathrm{CdO}$. Silver $\left(\mathrm{Ag}^{+}\right)$is a noble metal which has ionic radius of $1.22 \AA$ greater than that of $\mathrm{Cd}^{2+}(0.97 \AA)$ and exhibit high electrical conductivity facilitating fast electron transfer and low work function which favours the formation of good band alignment and the Ag-doped catalysts showed enhanced photocatalytic activity due to the surface plasmon resonance phenomenon under visible light [13]. Also, Ag-doped metal oxides exhibit strong absorption under visible light [14]. In view of these features, Ag-doping has been performed on $\mathrm{CdO}$ to enhance its resistivity, stability, band gap and to suppress the release of $\mathrm{Cd}^{2+}$ ions. In the present work, Ag-doped $\mathrm{CdO}(\mathrm{CdO}: \mathrm{Ag})$ thin films were deposited using perfume atomizer and the influence of Ag doping on some properties of $\mathrm{CdO}$ was investigated.

\section{Experimental details}

Pure and Ag-doped $\mathrm{CdO}$ (CdO:Ag) thin films were deposited using perfume atomizer with 0, 1, 2, and $3 \mathrm{wt} \% \mathrm{Ag}$ doping concentrations. Aqueous solution $(50 \mathrm{ml}$ in volume) containing $0.1 \mathrm{M}$ cadmium acetate $\left[\mathrm{Cd}\left(\mathrm{CH}_{3} \mathrm{COO}\right)_{2}\right]$ is used as the precursor solution to deposit pure $\mathrm{CdO}$ thin films. To this solution, 1, 2 and $3 \mathrm{wt} \%$ silver nitrate [ $\mathrm{Ag} \mathrm{NO}_{3}$ ] of the weight of cadmium acetate was added to deposit CdO:Ag thin films. The respective solutions when sprayed over hot glass substrates kept at $400{ }^{\circ} \mathrm{C}$ using perfume atomizer, pure and $\mathrm{Ag}$-doped $\mathrm{CdO}$ thin films were obtained. XRD patterns, SEM images, transmittance, $\mathrm{PL}$ spectra and electrical properties were analyzed using X'Pert PRO-Analytical diffractometer, HITACHI S-3000H scanning electron microscope, LAMBDA-35 UV-Vis-NIR double beam spectrophotometer, Varian Cary Eclipse fluorescence spectrophotometer and four point probe setup, respectively. Photodegradation ability of the CdO:Ag thin films against metanil yellow (MY) dye was judged by recording absorption spectra at $\lambda=433 \mathrm{~nm}$ at regular time intervals during the photocatalytic tests.

\section{Results and discussion}

\subsection{XRD studies}

Figure 1 shows the XRD patterns of $\mathrm{CdO}: \mathrm{Ag}$ thin films. The observed diffraction peaks labelled as ( $\left.\begin{array}{lll}1 & 1 & 1\end{array}\right),\left(\begin{array}{lll}2 & 0 & 0\end{array}\right),\left(\begin{array}{ll}2 & 2\end{array}\right.$ 0), (3 11 1) and (2 22 2) are well indexed to the face-centered cubic structure of CdO (JCPDS Cards No. 05-0640). No Ag related peaks were observed even for the heavily doped film, indicating that Ag has been homogeneously dispersed into the $\mathrm{CdO}$ matrix [15]. However the strongest peak ( $\left.\begin{array}{lll}1 & 1 & 1\end{array}\right)$ shifts towards lower $2 \theta$ value and becomes broader with $\mathrm{Ag}$ doping confirming that the $\mathrm{CdO}$ lattice is strained significantly when doped with $\mathrm{Ag}^{+}$ions. The average crystallite size (D) and the lattice strain $(\varepsilon)$ can be obtained using Williamson-Hall relation [16]:

$\frac{\beta \cos \theta}{\lambda}=\frac{1}{D}+\frac{\varepsilon \sin \theta}{\lambda}$

where $\lambda$ is the X-ray wavelength (1.5460 $\AA$ ) and $\theta$ is the Bragg's angle. From the $\mathrm{W}-\mathrm{H}$ plots, crystallite size and strain were calculated from the intersection of the line with the $Y$-axis and from the slope of the line, respectively and presented in Table 1. The crystallite size decreases and strain increases with increase in Ag doping concentration up to $2 \mathrm{wt} \%$ and an opposite behaviour is observed for the 3 wt $\%$ Ag-doped CdO film. Ag substitution on CdO matrix restrains grain boundary which limits the grain growth by

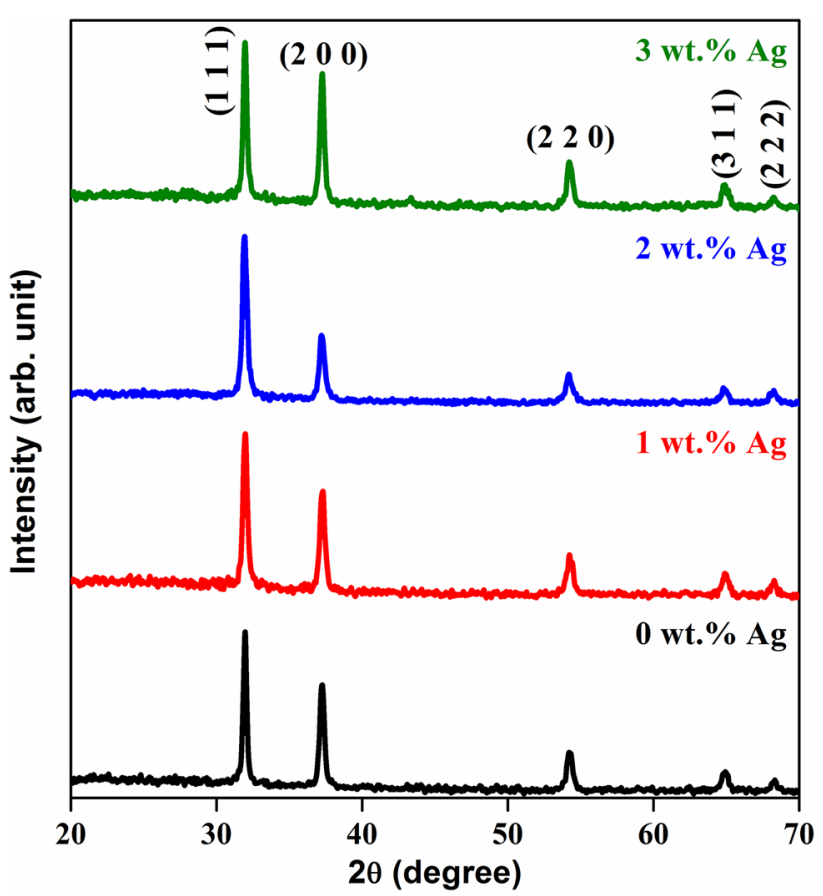

Fig. 1 XRD patterns of the CdO:Ag thin films 
Table 1 Crystallite size, strain, lattice parameter, band gap, electrical resistivity values and elemental composition of the CdO:Ag thin films

\begin{tabular}{|c|c|c|c|c|c|c|c|c|}
\hline \multirow[t]{2}{*}{$\begin{array}{l}\text { Ag doping concen- } \\
\text { tration (wt \%) }\end{array}$} & \multirow[t]{2}{*}{$\begin{array}{l}\text { Crystallite size } \\
{[D(n m)]}\end{array}$} & \multirow[t]{2}{*}{ Strain $\left(\varepsilon \times 10^{-3}\right)$} & \multirow[t]{2}{*}{$\begin{array}{l}\text { Lattice con- } \\
\text { stant 'a' }(\AA)\end{array}$} & \multirow[t]{2}{*}{$\begin{array}{l}\text { Band gap } \\
{\left[E_{g}(e V)\right]}\end{array}$} & \multirow[t]{2}{*}{ Resistivity $[\rho(\Omega-\mathrm{cm})]$} & \multicolumn{3}{|c|}{$\begin{array}{l}\text { Elemental composition } \\
\text { (at.\%) }\end{array}$} \\
\hline & & & & & & $\mathrm{Cd}$ & $\mathrm{O}$ & $\mathrm{Ag}$ \\
\hline 0 & 33 & 3.749 & 4.8481 & 2.45 & $0.71 \times 10^{-2}$ & 50.18 & 49.82 & - \\
\hline 1 & 28 & 4.497 & 4.8495 & 2.52 & $0.98 \times 10^{-3}$ & 49.49 & 47.46 & 3.05 \\
\hline 2 & 24 & 5.259 & 4.8599 & 2.58 & $0.16 \times 10^{-3}$ & 48.37 & 46.28 & 5.35 \\
\hline 3 & 26 & 4.808 & 4.8499 & 2.65 & $0.34 \times 10^{-3}$ & 47.80 & 47.30 & 4.90 \\
\hline
\end{tabular}

the symmetry breaking effects thereby decreasing grain size [17]. Ag when incorporated into the $\mathrm{CdO}$ matrix, $\mathrm{Cd}^{2+}$ ions may be replaced substitutionally by $\mathrm{Ag}^{+}$ions in the form of $\mathrm{Ag}_{\mathrm{cd}}$ acceptors or by occupying interstitial sites in the CdO lattice by forming $\mathrm{Ag}$ interstitials $\left(\mathrm{Ag}_{\mathrm{i}}\right)$ [18]. With Ag ions in the CdO lattice, repulsion between the crystallites restricts crystallites growth, thereby resulting in smaller grain size. The increase in lattice strain owing to the ionic size difference between $\mathrm{Ag}^{+}(1.22 \AA)$ and $\mathrm{Cd}^{2+}$ $(0.97 \AA)$ might have resulted in the decreased crystallite size values observed for the 1 and $2 \mathrm{wt} \% \mathrm{Ag}$-doped CdO thin films. The slight increment in the crystallite size value observed for the 3 wt\% Ag-doped CdO film might be due to the increase in the number of interstitial $\mathrm{Ag}^{+}$ions. Besides the strain induced in $\mathrm{CdO}$ matrix due to the substitution of larger sized dopant ion, dislocations and natural defects play a vital role in the increment observed in the lattice parameter values of the CdO:Ag thin films (Table 1).

\subsection{Surface morphology and elemental analysis}

The SEM images of the CdO:Ag thin films are pictured in Fig. 2. Cauliflower shaped grains were observed for all the films. Interconnected cauliflower shaped grains with larger sizes were observed for the undoped CdO (Fig. 2a). With Ag doping, the surface of pure $\mathrm{CdO}$ got modified with tightly packed cauliflower shaped grains with reduced sizes (Fig. 2b, c). Reduced grain size was observed for the $\mathrm{CdO}$ film doped with 2 wt $\%$ Ag concentration, which very much obeyed the results obtained in the XRD studies. In a solid-solid interface, the free energies of the interfaces and grain boundaries which depend on the crystallographic orientation of the neighbouring grains frequently determine the stability of the system. With Ag doping, the grain size decreases as evinced from the SEM images inferring an increase in grain boundaries which makes the $\mathrm{CdO}$ lattice more stable.

Figure 3 shows the EDX spectra of the CdO:Ag thin films. $\mathrm{Ag}$ is observed for all the doped films in addition to $\mathrm{Cd}$ and $\mathrm{O}$. The content of $\mathrm{Cd}, \mathrm{O}$ and $\mathrm{Ag}$ present in the films are compiled in Table 1. The increased Ag content confirmed that $\mathrm{Ag}^{+}$ions are successfully incorporated into the $\mathrm{CdO}$ lattice either substitutionally or interstitially.

\subsection{Optical studies}

Increased transparency and a shift of the absorbance edge towards lower wavelength side were observed for the Agdoped $\mathrm{CdO}$ thin films from their transmittance spectra (Fig. 4). Increased transparency may be due to less scattering effects, structural homogeneity and improved crystallinity as realized earlier [19]. Improved surface smoothness due to decreased crystallite size might also have increased the transparency of the doped films [20]. From the Tauc's plots $\left[(\mathrm{ahv})^{2}\right.$ vs. hv] (Fig. 5), the optical band gap $\left(\mathrm{E}_{\mathrm{g}}\right)$ values of the CdO:Ag thin films were estimated by connecting linear portion of the plots to hv axis at $\alpha=0$ and compiled in Table 1. The increased band gap values with Ag doping may be attributed to quantum confinement effect according to which widened band gap occurs due to smaller crystallites which due to individual confinement of electrons and holes shift the absorption threshold to shorter wavelength [7].

\subsection{PL studies}

Emission bands were observed at 407, 486, 525, 569, 591 and $600 \mathrm{~nm}$ for the Ag-doped $\mathrm{CdO}$ thin films in the PL spectra recorded at room temperature (Fig. 6). The band at $407 \mathrm{~nm}$ takes place due to the relaxation of electrons when they move from the conduction band to the valence band in Cd interstitial sites [8]. The radiative recombination peak of photogenerated hole with an electron which occupies the oxygen vacancy is observed at $486 \mathrm{~nm}$ [21]. The electronic transition of ionized oxygen vacancies from the deep level donor to the valence band is responsible for the emission peak at $525 \mathrm{~nm}$ [22]. The yellow emission peak related to defect levels associated with $\mathrm{O}$ vacancies or $\mathrm{Cd}$ interstitials is observed at $569 \mathrm{~nm}$ [23]. The donor-acceptor pair (DAP) peaks at 591 and $600 \mathrm{~nm}$ may be due to radiative transitions from the surface defect states [24]. All the doped films have lesser PL intensity than the undoped film and as the PL intensity is directly associated with the 
Fig. 2 SEM images of the CdO thin films doped with a 0 wt\%, b 1 wt $\%$, c 2 wt $\%$ and $\mathbf{d} 3$ wt $\%$ Ag concentrations
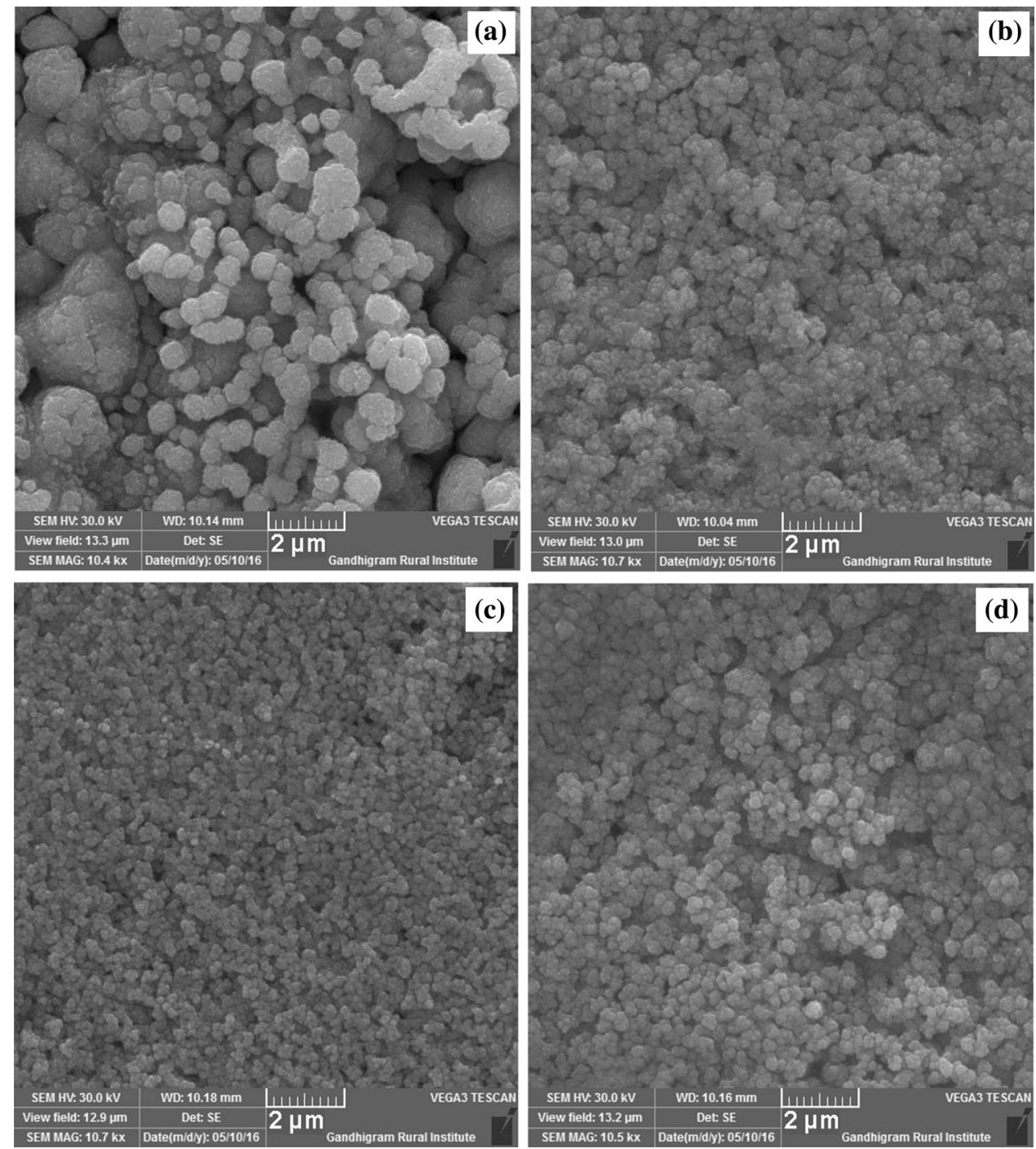

recombination of electrons and holes, their lower intensities suggest a delay in their recombination rate, thereby enhancing their photocatalytic performance (Sect. 3.6).

\subsection{Electrical studies}

The electrical resistivity values of the CdO:Ag thin films deposited with 0, 1, 2 and 3 wt\% Ag doping concentrations measured using a four point setup are presented in Table 1. The electrical resistivity value of $0.71 \times 10^{-2}$ $\Omega \mathrm{cm}$ observed for pure $\mathrm{CdO}$ exactly matched the earlier reported value [25]. With Ag doping up to the $2 \mathrm{wt} \%$ electrical resistivity seems to decrease drastically above this concentration it slightly increases. For each $\mathrm{Ag}^{+}$ion replacing $\mathrm{Cd}^{2+}$ ion, one electron is released in the $\mathrm{CdO}$ lattice which in turn increases the carrier concentration, thereby reducing the resistivity of the Ag-doped $\mathrm{CdO}$ thin films [26]. However for the $3 \mathrm{wt} \% \mathrm{Ag}$ doping, the resistivity seems to increase slightly due to the occupancy of $\mathrm{Ag}^{+}$ ions in the interstitial places in the $\mathrm{CdO}$ lattice, thereby causing lattice distortion which decreases the electrical mobility. Also, the increase of ionized impurities scattering and electron-electron scattering increases the resistivity of the $3 \mathrm{wt} \% \mathrm{Ag}$-doped CdO thin films [27].

\subsection{Photocatalytic activity}

The photocatalytic performance of the CdO:Ag catalysts was tested against metanil yellow (MY) dye under visible light. The CdO:Ag catalysts with 0, 1, 2 and $3 \mathrm{wt} \%$ Ag doping concentrations were immersed in four sets of aqueous solution $(10 \mathrm{~mL}$ ) containing $0.025 \mathrm{M} \mathrm{MY}$ dye. Before visible light exposure, the dye solution with the CdO:Ag catalysts was kept under dark to achieve adsorption-desorption equilibrium [28]. The photodegradation ability of the CdO:Ag catalysts was monitored by taking absorption spectra of MY $(\lambda=433 \mathrm{~nm})$. Figure 7 shows the absorbance spectra of MY with CdO:Ag catalysts.

\section{SN Applied Sciences}



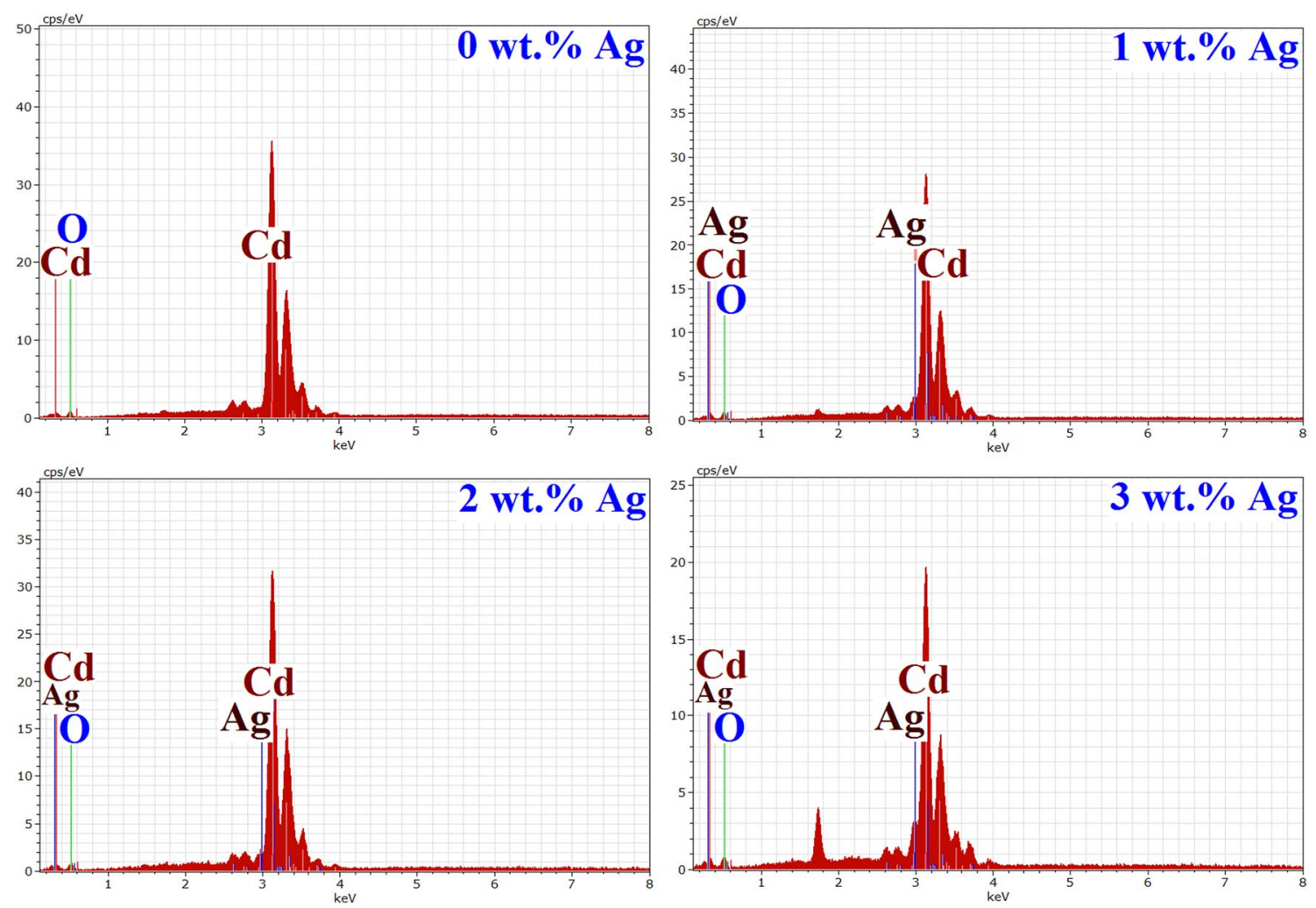

Fig. 3 EDX spectra of the CdO:Ag thin films
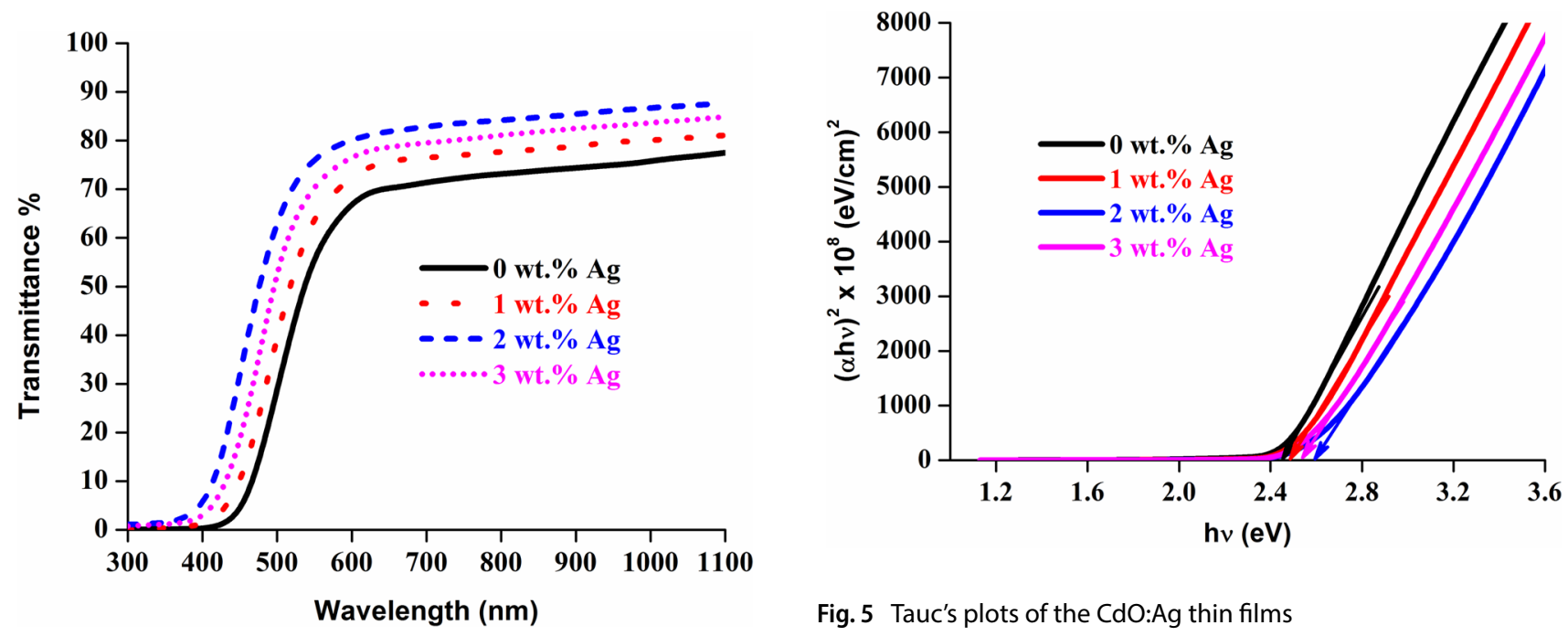

Fig. 5 Tauc's plots of the CdO:Ag thin films

Fig. 4 Transmittance spectra of the CdO:Ag thin films

The MY absorption band decreased with increase in irradiation time, which meant that MY gradually photodegraded under the exposure of visible light and the decrement observed for the CdO:Ag catalysts was faster than pure $\mathrm{CdO}$ which confirmed that $\mathrm{Ag}^{+}$ions effectively improves the photocatalytic activity of $\mathrm{CdO}$.

From the concentration of the dye under dark $\left(\mathrm{C}_{0}\right)$ and light (C) conditions, the degradation efficiencies of the CdO:Ag catalysts were calculated using Eq. (2) [29] and are shown in Fig. 8.

$\eta=\left(1-C / C_{0}\right) \times 100$ 


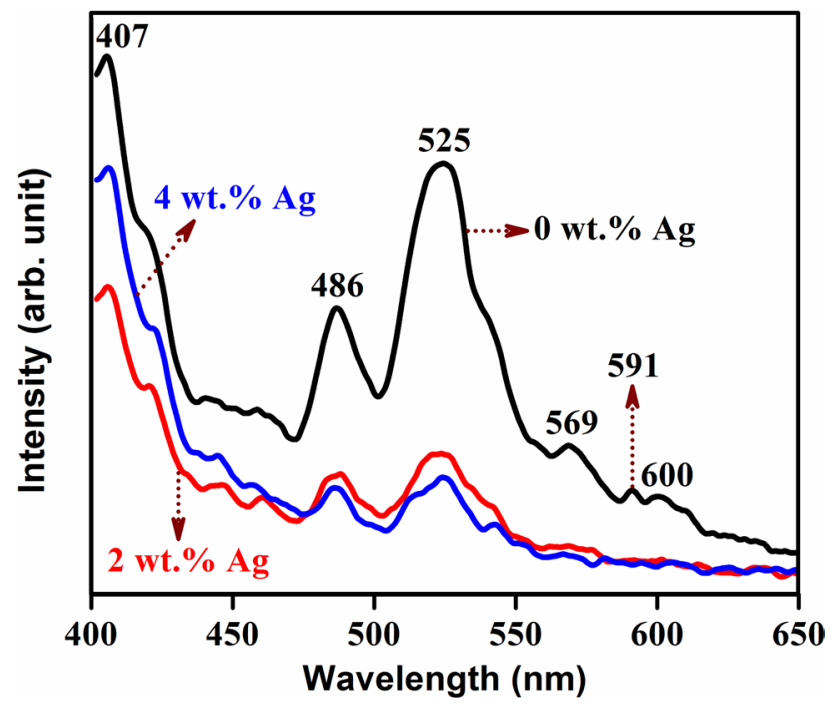

Fig. 6 PL spectra of the CdO:Ag thin films

Compared to that of pure $\mathrm{CdO}$, the Ag-doped $\mathrm{CdO}$ catalysts showed enhanced photodegradation efficiencies and the 2 wt\% Ag-doped CdO catalyst showed the highest degradation efficiency. The enhancement in the degradation efficiency observed with Ag doping may be due to the following reasons: (1) Synergic action of Agdoped CdO [17], (2) increased Cd vacancies accompanied by oxygen vacancies [30], (3) enhanced electron-hole separation as the Fermi level of $\mathrm{Ag}$ is located close to the conduction band of $\mathrm{CdO}$ [31] and (4) surface-plasmon resonance effect [32].

A possible mechanism was formulated for the photocatalytic acitivty of the CdO:Ag catalysts and is shown in Fig. 9. As $\mathrm{CdO}$ was irradiated by visible light to form photogenerated electrons and holes, the existence of Ag nanoparticles in the $\mathrm{CdO}$ matrix plays an important role in the enhancement of photocatalytic activity of $\mathrm{CdO}$ against metanil yellow. It is well known that the metal Ag nanoparticles can remarkably enhance the absorption in the visible region because of surface plasmonic resonance (SPR) effect [33]. Due to this effect, Ag nanoparticles increased the absorption range of the CdO:Ag catalysts and enhanced the absorption intensity. Therefore, under the same light irradiation conditions, more photogenerated charge carriers are produced and enhanced photocatalytic activity was realized. Under the irradiation of visible light, due to the synergic effect, the photogenerated electrons of pure $\mathrm{CdO}$ was rapidly transferred to the surface of Ag. As Ag nanoparticles have a Fermi level lower than the
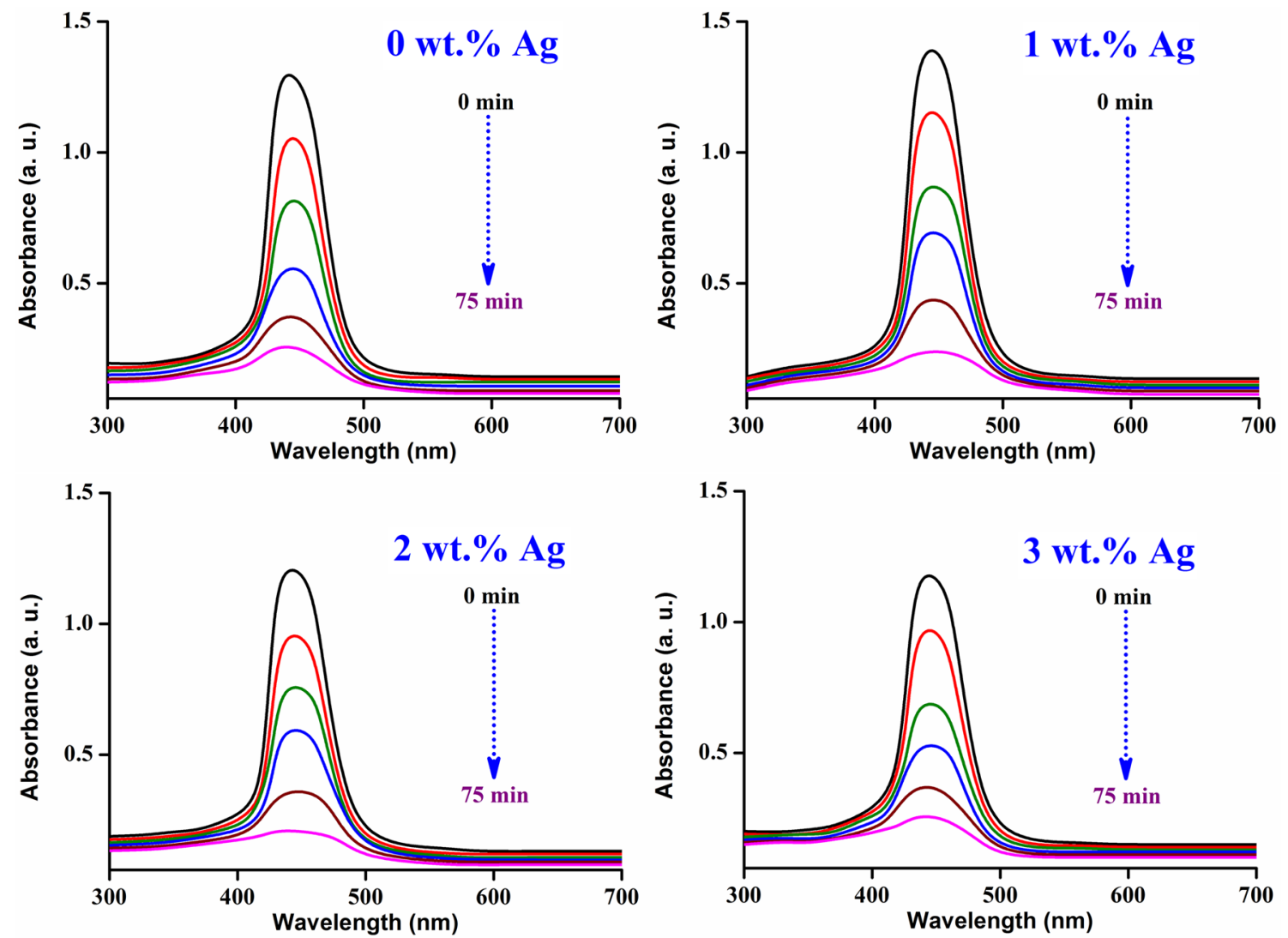

Fig. 7 Absorbance spectra of a 0 wt $\%$, b 1 wt $\%$, c 2 wt $\%$ and d 3 wt $\%$ Ag-doped CdO catalysts 


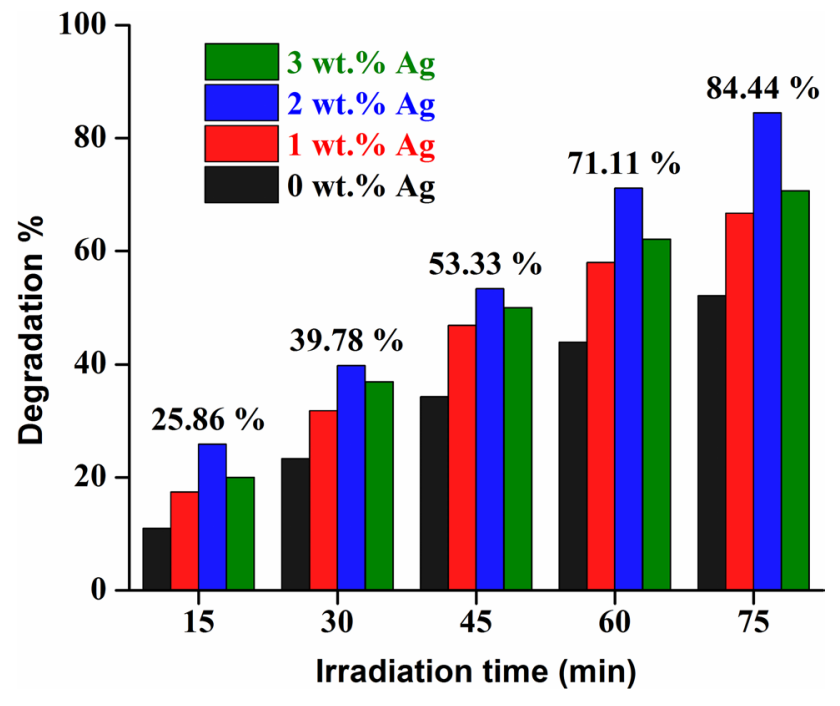

Fig. 8 Photodegradation efficiencies of the CdO:Ag catalysts

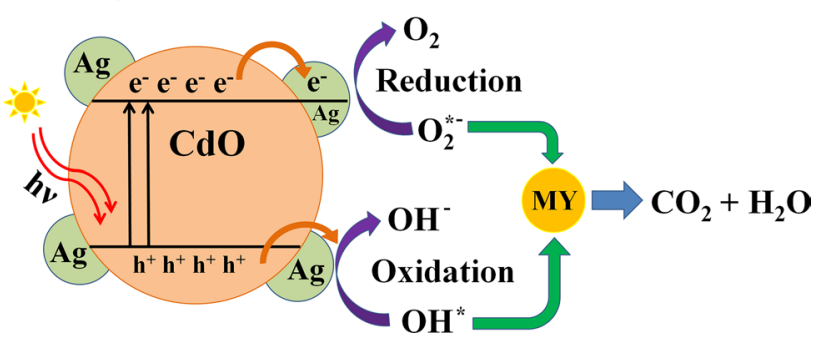

Fig. 9 Photocatalytic mechanism of the CdO:Ag catalysts

conduction band of $\mathrm{CdO}$ it can collect the electrons that are excited from $\mathrm{CdO}$ [34]. The injected electrons react with adsorbed oxygen on the $\mathrm{CdO}$ surface to form $\mathrm{O}_{2}^{*}$ radicals. Meanwhile, the photo-induced holes left in the valence band of $\mathrm{CdO}$ diffuse effectively to the surface of the catalyst and reacts with water to form $\mathrm{OH}^{*}$ radicals. The $\mathrm{O}_{2}^{*}$ and $\mathrm{OH}^{*}$ radicals are the reactive species that degrade the dye molecules with the release of $\mathrm{CO}_{2}$ and $\mathrm{H}_{2} \mathrm{O}$ [35]. The chemical reactions involved in the photocatalytic mechanism of the CdO:Ag catalysts could be summarized as follows [36]:

$$
\begin{aligned}
& \mathrm{CdO}: \mathrm{Ag}+h v \rightarrow \mathrm{CdO}: \mathrm{Ag}\left(\mathrm{CBe}^{-}\right)+\mathrm{CdO}: \mathrm{Ag}\left(\mathrm{VBh}^{+}\right) \\
& h^{+}+\mathrm{H}_{2} \mathrm{O} \rightarrow \mathrm{OH}^{*} \\
& e^{-}+\mathrm{Ag} \rightarrow \mathrm{Ag}^{-} \\
& \mathrm{Ag}^{-}+\mathrm{O}_{2} \rightarrow \mathrm{O}_{2}^{*-} \\
& \mathrm{O}_{2}^{*-}+e^{-}+2 \mathrm{H}^{+} \rightarrow \mathrm{H}_{2} \mathrm{O}_{2} \\
& \mathrm{H}_{2} \mathrm{O}_{2}+e^{-} \rightarrow \mathrm{OH}^{*}+\mathrm{OH}^{-}
\end{aligned}
$$

$\mathrm{MY}+\mathrm{OH}^{*} \rightarrow \mathrm{CO}_{2}+\mathrm{H}_{2} \mathrm{O}$ (Degraded products $)$

The slight decrement in the degradation efficiency observed for the $3 \mathrm{wt} \% \mathrm{Ag}$-doped $\mathrm{CdO}$ catalyst might be due to the increased recombination of electron-hole pairs through quantum tunnelling.

The photocatalytic degradation kinetic of the $\mathrm{CdO}: \mathrm{Ag}$ catalysts were investigated based on the pseudo first order kinetic model illustrated by Langmuir-Hinshelwood according to the equation:

$k=\frac{\ln \left(C_{0} / C\right)}{t}$

where $\mathrm{k}$ is the apparent first order rate constant, $\mathrm{C}$ and $\mathrm{C}_{\mathrm{o}}$ represents the concentration of MY under light and dark conditions, respectively. From the plots of $\ln \left(\frac{C_{0}}{C}\right)$ versus irradiation time (not shown), the degradation rate constant values were calculated from their slopes. The $k$ values were $0.02014,0.02592,0.02957$ and $0.02762 \mathrm{~min}^{-1}$ for the 0, 1, 2 and 3 wt $\%$ Ag-doped CdO catalysts, respectively. The highest $k$ value obtained for the 2 wt $\%$ CdO:Ag catalyst supports for its high degradation efficiency.

Recycling tests performed for the $2 \mathrm{wt} \% \mathrm{Ag}$-doped CdO catalyst (Fig. 10) confirmed that up to four cycles of catalytic tests, the degradation efficiency remains the same and only for the fifth cycle a slight decrement in efficiency is observed. The improvement in the stability of $\mathrm{CdO}$ through $\mathrm{Ag}$ doping might be responsible for the good recycling performance of the CdO:Ag catalysts. Thus, the CdO:Ag catalysts are well suited for practical applications.

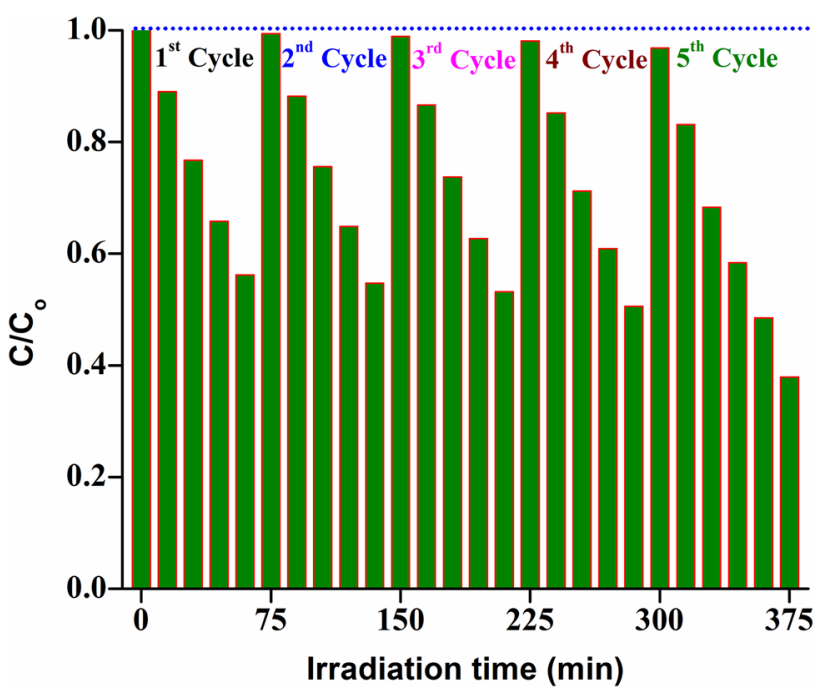

Fig. 10 Recycle tests of the 2 wt\% Ag-doped CdO catalyst 


\section{Conclusion}

CdO:Ag thin films with 0, 1, 2 and 3 wt\% Ag concentration were deposited using perfume atomizer. The $\mathrm{CdO}: \mathrm{Ag}$ thin films with 1, 2 and $3 \mathrm{wt} \%$ Ag doping concentrations showed better degradation efficiencies against metanil yellow dye, than the undoped film. The enhanced degradation efficiencies observed for the doped catalyst might be due to the synergetic and surface-plasmon resonance effects of Ag. The 2 wt\% Ag-doped CdO catalyst exhibited a maximum degradation efficiency of $84.44 \%$ after 75 min light irradiation due to its reduced crystallite size, large surface area and increased band gap values which was well acknowledged from the XRD, SEM and optical studies. Thus, the CdO:Ag catalysts seem to be very effective in degrading organic dyes.

Acknowledgements The authors are thankful to the Gandhigram Rural University, Dindugal, Tamilnadu for the SEM and EDX analyses.

\section{Compliance with ethical standards}

Conflict of interest The authors declare that they have no conflict of interest.

Ethical approval All the authors declare that the article is original and all are aware of its contents and they approve for its submission. The authors also confirm that the described work has not been published before; it is not under consideration for publication anywhere else and publication has been approved by all co-authors and the responsible authorities of the institute where the work has been carried out. No conflict of interest exists in the article. The authors also declare that no research has been performed on human participants or animals. The authors declare that if the article is accepted it will not be published elsewhere in the same form in any language without the written consent of the publisher.

\section{References}

1. Dhivya P, Prasad AK, Sridharan M (2012) Nanostructured cadmium oxide thin films for hydrogen sensor. Int J Hydrog Energy 37:18575-18578

2. Rajput JK, Pathak TK, Kumar V et al (2017) Influence of sol concentration on $\mathrm{CdO}$ nanostructured with gas sensing application. Appl Surf Sci 409:8-16

3. Dou Y, Egdell RG, Walker T et al (1998) N-type doping in CdO ceramics: a study by EELS and photoemission spectroscopy. Surf Sci 398:241-258

4. Tadjarodi A, Imani M, Kerdari H (2013) Experimental design to optimize the synthesis of $\mathrm{CdO}$ cauliflower-like nanostructure and high performance in photodegradation of toxic azo dyes. Mater Res Bull 48:935-942

5. Usharani K, Balu AR, Nagarethinam VS (2016) Enhanced properties of $\mathrm{Zn}$-, Mg-incorporated $\mathrm{CdO}$ films through $\mathrm{Cl}$ doping. Surf Eng 32:829-833
6. Liu CP, Foo Y, Kamruzzaman M et al (2016) Effects of free carriers on the optical properties of doped CdO for full-spectrum photovoltaics. Phys Rev Appl 6:064018-064029

7. Usharani K, Balu AR, Nagarethinam VS et al (2015) Characteristic analysis on the physical properties of nanostructured $\mathrm{Mg}$-doped $\mathrm{CdO}$ thin films-doping concentration effect. Prog Nat Sci Mater Int 25:251-257

8. Manjula N, Pugalenthi M, Nagarethinam VS et al (2015) Effect of doping concentration on the structural, morphological, optical and electrical properties of $\mathrm{Mn}$-doped $\mathrm{CdO}$ thin films. Mater Sci Pol 33:774-781

9. Aydemir S, Kose S, Killickaya MS et al (2014) Influence of Al doping on microstructure and optical properties of sol-gel derived $\mathrm{CdO}$ thin films. Superlattices Microstruct 71:72-81

10. Ganjiani Z, Jamali-Sheini F, Yousefi R (2016) Electrochemical synthesis and physical properties of Sn-doped CdO nanostructures. Superlattices Microstruct 100:988-996

11. Antosoly D, Ilangovan S, Suganya M et al (2018) Optical and magnetic properties of $\mathrm{CdO}$ thin films doped with $\mathrm{Ba}^{2+}$ (cation) ions. Mater Res Innov 22:237-241

12. Antosoly D, llangovan $S$, Nagarethinam VS et al (2018) Modulation of microstructure and magnetic properties of Sr-doped CdO films. Surf Eng 34:682-688

13. Lin $\mathrm{DD}, \mathrm{Wu} \mathrm{H}$, Zhang $\mathrm{R}$ et al (2009) Enhanced photocatalysis of electrospun $\mathrm{Ag}-\mathrm{ZnO}$ heterostructured nanofibers. Chem Mater 21:3479-3484

14. Li Y, Zhao X, Fan W (2011) Structural, electronic and optical properties of Ag-doped $\mathrm{ZnO}$ nanowires: first principles study. J Phys Chem C 115:3552-3557

15. Turgut G, Aksoy G, Iskenderoglu D et al (2018) The effect of Eu loading on the some physical features of CdO. Ceram Int 44:3921-3928

16. Suganya M, Balu AR, Balamurugan S et al (2018) Photoconductive, photocatalytic and antifungal properties of PbS: Mo nanoparticles synthesized via precipitation method. Surf Interfaces 13:148-156

17. Ali T, Ahmed A, Alam U et al (2018) Enhanced photocatalytic and antibacterial activities of $\mathrm{Ag}$-doped $\mathrm{TiO}_{2}$ nanoparticles under visible light. Mater Chem Phys 212:325-335

18. Razeen AS, Gadallah AS, El-Nahass MM (2018) Effect of Ag doping on the properties of $\mathrm{ZnO}$ thin films for UV silmulated emission. Physica B Cond Matt 538:131-137

19. Usharani K, Balu AR (2016) Properties of spray deposited Zn, $\mathrm{Mg}$ incorporated $\mathrm{CdO}$ thin films. J Mater Sci: Mater Electron 27:2071-2078

20. Selvan G, Abubacker MP, Balu AR (2016) Structural, optical and electrical properties of $\mathrm{Cl}$-doped ternary $\mathrm{CdZnS}$ thin films towards optoelectronic applications. Optik 127:4943-4947

21. Dong W, Zhu C (2003) Optical properties of surface-modified CdO nanoparticles. Opt Mater 22:227-233

22. Balamurugan S, Balu AR, Usharani K et al (2016) Synthesis of CdO nanopowders by a simple soft chemical method and evaluation of their antimicrobial activities. Paci Sci Rev A 18:228-232

23. Nallendran R, Selvan G, Balu AR (2018) Photoconductive and photocatalytic properties of CdO-NiO nanocomposite synthesized by a cost effective chemical method. J Mater Sci Mater Electron 29:11384-11393

24. Manjula N, Suganya M, Prabha D et al (2017) Optoelectronic, magnetic and antibacterial properties of $\mathrm{CdO}$ thin films doubly doped with Mn (cationic) and F (anionic) ions. J Mater Sci Mater Electron 28:7615-7621

25. Raja N, Nagarethinam VS, Balu AR (2019) Aging effect of the precursor solution on the structural, morphological and optoelectrical properties of spray deposited $\mathrm{CdO}$ thin films. Mater Sci Poland 37:1-7 
26. Acharya AD, Sarwam B, Panda R et al (2014) Tuning of TCO properties of $\mathrm{ZnO}$ by silver addition. Superlattices Microstruct 67:97-109

27. Taha H, Jiang ZT, Henry DJ et al (2018) Improved mechanical properties of sol-gel derived ITO thin films via Ag doping. Mater Today Commun 14:210-224

28. Samiyammal P, Parasuaraman K, Balu AR (2019) Improved magnetic and photocatalytic properties of spray deposited $(\mathrm{Li}+\mathrm{Co})$ codoped CdS thin films. Superlattices Microstruct 129:28-39

29. Nallendran R, Selvan G, Balu AR (2019) $\mathrm{CdO}-\mathrm{Fe}_{3} \mathrm{O}_{4}$ nanocomposite with enhanced magnetic and photocatalytic properties. Mater Sci Poland 37:100-107

30. Hosseini SM, Abdolhosseini Sarsari I, Kameli P et al (2015) Effect of Ag doping on structural, optical and photocatalytic properties of ZnO nanoparticles. J Alloys Compd 640:408-415

31. Sarkar S, Biswas S, Sarkar M et al (2018) Ag deposition effects on the photocatalytic activity of nanoparticulate $\mathrm{TiO}_{2}$-Comparision of gamma irradiation and UV irradiation methods. Nanostruct Nanoobj 16:134-143

32. Fageria P, Gangopadhyay S, Pande S (2014) Synthesis of $\mathrm{ZnO} / \mathrm{Au}$ and $\mathrm{ZnO} / \mathrm{Ag}$ nanoparticles and their photocatalytic application using UV and visiblie light. RSC Adv 4:24962-24972
33. Han Z, Wang N, Fan H, Ai S (2017) Ag nanoparticles loaded on porous graphitic carbon nitride with enhanced photocatalytic activity for degradation of phenol. Sol State Sci 65:110-115

34. Sun J, Zhang Y, Cheng J et al (2014) Synthesis of Ag/AgCl/Zn- $\mathrm{Cr}$ LDHs composite with enhanced visible light photocatalytic performance. J Mol Catal A Chem 382:146-153

35. Fan $\mathrm{H}$, Zhu J, Sun J et al (2013) Ag/AgBr/Co-Ni-NO 3 layered double hydroxide nanocomposites with highly adsorptive and photocatalytic properties. Chem Eur J 19:2523-2530

36. Manjula N, Selvan G, Balu AR (2017) Improved photodegradation activity of $\mathrm{SnO}_{2}$ nanopowder against methyl orange dye through Ag doping. J Mater Sci Mater Electron 29:3657-3664

Publisher's Note Springer Nature remains neutral with regard to jurisdictional claims in published maps and institutional affiliations. 